\title{
The prognostic value of serum CA 19-9 for patients with advanced lung adenocarcinoma
}

\author{
Yuki Sato1, Daichi Fujimoto 1*, Keiichiro Uehara², Ryoko Shimizu1, Jiro Ito', Mariko Kogo', Shunsuke Teraoka1, \\ Ryoji Kato', Kazuma Nagata', Atsushi Nakagawa', Kojiro Otsuka', Hiroshi Hamakawa, Yutaka Takahashi', \\ Yukihiro Imai ${ }^{2}$ and Keisuke Tomii ${ }^{1}$
}

\begin{abstract}
Background: This study aimed to assess the prognostic accuracy of serum CA 19-9 in patients with advanced lung adenocarcinoma.

Methods: We retrospectively reviewed data of 246 patients who were diagnosed at our institute with advanced (stage IIIB or IV) lung adenocarcinoma between March 2006 and December 2012. We excluded patients who received no chemotherapy, or for whom we had no data on pre-treatment tumor markers. We also evaluated 116 consecutive resected specimens from patients with clinical stage I lung adenocarcinoma pathologically.

Results: The 76 (31\%) patients who were CA 19-9+ had shorter overall survival (OS) than CA 19-9- group (12.5 vs 26.2 months, $P=0.005$ ). Cox's multivariate regression analysis identified Eastern Cooperative Oncology Group Performance Status 0 or $1(P<0.001)$, mutated epidermal growth factor receptor $(E G F R)$ status $(P<0.001)$, stage IIIB $(P<0.001)$, CYFRA $21-1^{-}(P<0.001), C A 19-9^{-}(P=0.005)$ and use of platinum doublet therapy $(P=0.034)$ as independent predictors of longer OS. We stratified patients by CA 19-9 and CYFRA 21-1 as double positive (CA 19-9 $/$ /CYFRA 21-1 ${ }^{+}$, $n=59$ ), single positive (either CA19-9 $9^{+}$or CYFRA $21-1^{+}, n=113$ ), or double negative (CA 19-9 ${ }^{-} /$CYFRA $21-1^{-}, n=74$ ). Their respective OS were 10.0, 23.3 and 31.8 months $(P<0.001)$. Pathological analysis also correlated CA 19-9 expression with malignant features such as vessel invasion, pleural invasion, cancer invasive factors and mucin production.
\end{abstract}

Conclusions: CA 19-9 and CYFRA 21-1 are independent prognostic markers in patients with advanced lung adenocarcinoma. Combined use of CA 19-9 and CYFRA 21-1 provides further prognostic information in patients with advanced lung adenocarcinoma.

Keywords: CA 19-9, CYFRA 21-1, Lung adenocarcinoma, Tumor marker, Prognostic marker

\section{Background}

Lung cancer is the leading cause of cancer death worldwide. Unfortunately, most lung cancers are already unresectable and metastatic at initial diagnosis [1,2]. Overall survival (OS) of patients with advanced lung adenocarcinoma (ALAD) is still very poor, despite progress in treatment and chemotherapy. ALAD prognosis can be assessed through various factors, such as pathologic characteristics, imaging

\footnotetext{
* Correspondence: daichianzen@yahoo.co.jp

${ }^{1}$ Department of Respiratory Medicine, Kobe City Medical Center, General Hospital, 2-1-1 Minatojima-minamimachi, Chuo-ku, Kobe 650-0047, Japan

Full list of author information is available at the end of the article
}

features, and oncogenes, but identification of more accurate prognostic markers is imperative.

Measurement of tumor markers is a non-invasive means to predict prognosis, and is therefore used in daily clinical practice [3]. Earlier investigations of the relationships between prognosis and serum cytokeratin 19 fragments (CYFRA 21-1), carcinoembryonic antigen (CEA) or neuron-specific enolase (NSE) in ALAD patients found only CYFRA 21-1 to be an independent prognostic marker among them [4-6]. Therefore, identification of another independent prognostic tumor marker would have great value in managing these patients. 
Carbohydrate antigen 19-9 (CA 19-9) is a tumorassociated antigen originally isolated from a human colorectal cancer cell line in 1979 by Koprowski [7]. Since development of radioimmunometric assays, CA 19-9 has been used to monitor various cancer types, and is used as a prognostic marker in pancreatic, colon, and stomach adenocarcinoma [8-15].

Although patients with ALAD who show extremely high serum levels of CA 19-9 are reportedly have poor prognoses, the relationship between serum CA 19-9 and prognosis in lung adenocarcinoma has not been studied yet $[16,17]$. We hypothesized that CA $19-9$ is a prognostic marker for ALAD patients.

The purpose of this study was to investigate the clinical utility of CA 19-9 as a prognostic marker in ALAD patients, and to improve its prognostic accuracy.

\section{Methods}

\section{Study subjects}

We retrospectively analyzed 433 patients diagnosed advanced (stage IIIB or IV) lung adenocarcinoma at Kobe City Medical Center General Hospital between March 2006 and December 2012. We excluded patients who received no chemotherapy $(n=71)$, or for whom no data on tumor markers (CEA, CYFRA 21-1 and CA 19-9) before receiving chemotherapy was available $(n=116)$. Patients who reported never having smoked were defined as never-smokers, those who had smoked within 1 year of the diagnosis were categorized as current smokers, and the rest were considered to be former smokers. All patients were classified by clinical stage according to the $7^{\text {th }}$ edition TNM (tumor, node, metastasis) classification [18]. OS was measured from the diagnosis of lung cancer until death from any cause or the end of the follow-up. We isolated tumor DNA from various specimens and analyzed epidermal growth factor receptor gene (EGFR) mutation status at exons 18-21, using the peptide nucleic acid-locked nucleic acid PCR clamp methods, as described previously [19]. We retrospectively analyzed the presence of intestinal pneumonia, non-tuberculous mycobacteriosis (NTM) infection, bronchiectasis, and diffuse panbronchiolitis by reviewing patients' charts and radiological records.

\section{Determination of tumor markers concentration}

Serum samples were obtained to determine tumor markers CEA, CYFRA 21-1 and CA 19-9 as a part of routine evaluations within 28 days before starting chemotherapy. The concentration of each tumor makers was measured using LumiPulse Presto kit (Fujirebio Inc., Tokyo, Japan). It utilizes the chemiluminescent enzyme immunoassay (CLEIA) principle and is a fully automated assay [20]. The CLEIA method uses $1.6 \mathrm{ng} / \mathrm{mL}$ as the upper limit of normal (ULN) serum CYFRA 21-1 level in healthy individuals [21]. For this study, we set the cutoff value for CYFRA 21-1 at
$2.2 \mathrm{ng} / \mathrm{mL}$, which was used in a previous study that showed the prognostic impact of CYFRA 21-1 in patients with $\mathrm{ALAD}$, and is the mean value for healthy subjects $+3 \mathrm{SD}$ (standard deviation) [4]. The cutoff values for serum CEA and CA 19-9 were set at $5.0 \mathrm{ng} / \mathrm{mL}$ and $37.0 \mathrm{U} / \mathrm{mL}$, which are their respective ULNs [22, 23]. This testing was performed at the Department of Laboratory Medicine at our hospital.

\section{Pathological analysis}

Additionally, we retrospectively analyzed post-operative specimens from patients with clinical stage I lung adenocarcinoma who underwent surgery at our hospital between January 2008 and May 2010. We evaluated the presence of vessel invasion, pleural invasion, lymph node metastasis and postoperative pathological stage. The presence of mucin was also assessed using diastase-resistant periodic acid Schiff (D-PAS) staining in all samples with $5 \%$ increments (Fig. 1a, b) [24, 25]. We tested CA 19-9 expression, immunohistochemically (IHC), using the 116-NS-19-9 antibody (Covance Inc., Princeton, USA). We applied the expression score, which was described previously [26-28]. Percentages of CA 19-9 ${ }^{+}$tumor cells (proportion score) was scored as 0 : none (0\%); 1: 1-10\%; 2 : 11-30\%; 3: 31-50\%; 4: 51-70\%; and 5: 71-100\% of each tumor sample. The intensity of staining (intensity score) was scored as 0: no staining; 1 : weak staining; 2 : moderate staining; and 3: strong staining in $>10 \%$ of cancer cells (Fig. 1c-f). The proportion score and intensity score were added to yield a total expression score of 0-8; samples that scored $\geq 3$ were defined as CA $19-9^{+}$. We defined cases with at least one of the pathologic invasive factors-vessel invasion, pleural invasion, or lymph node metastasis-as positive for cancer invasive factors [29]. All pathological analyses were evaluated by two experienced pathologists who were unaware of the patients' conditions.

\section{Statistical analysis}

Continuous variables were analyzed using Student's t-test. Dichotomous variables were analyzed using Fisher's exact test. Correlations between CA 19-9 levels and CYFRA 21-1 levels were assessed using Spearman's rank-based correlation test. The Kaplan - Meier method was used to estimate survival outcomes; groups were compared using the log-rank test. Cox's proportional hazard models were fitted to determine associations between patient characteristics and survival outcomes. A multivariate Cox proportional hazard model was developed on all clinically important factors (age, sex, smoking status, ECOG PS, EGFR status, stage, positivity of serum CEA, CYFRA 21-1 and CA 19-9, and platinum doublet therapy administration). The results are expressed as hazard ratios (HRs) with $95 \%$ confidence intervals (CI). All tests were two-tailed. A value of $P<0.05$ was considered to indicate significance. We conducted 

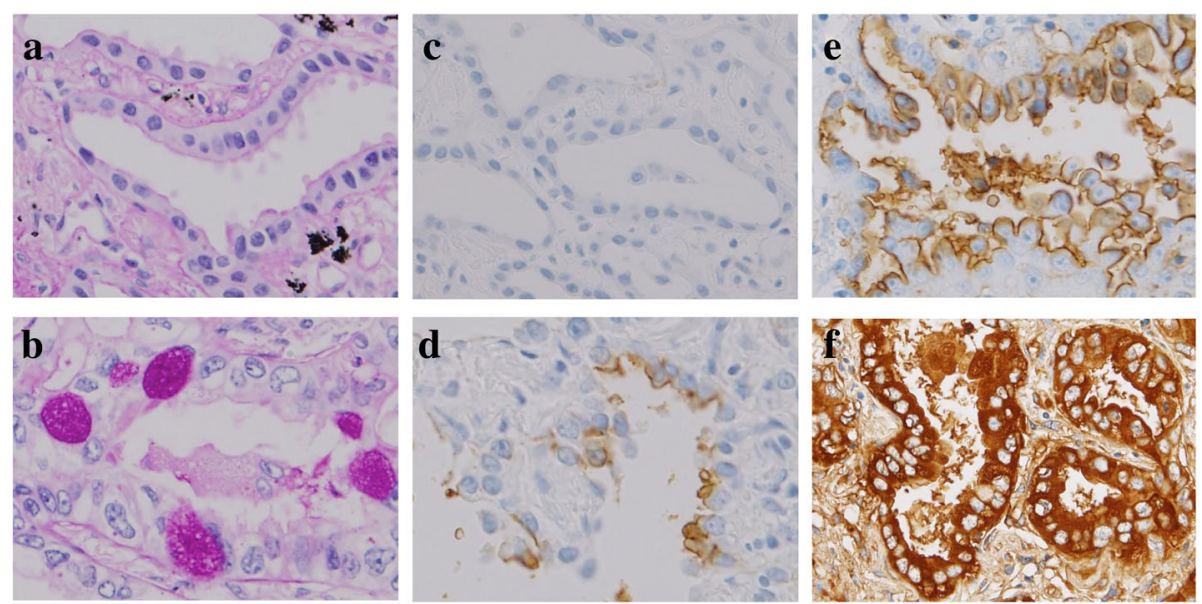

Fig. 1 a, b Stage I adenocarcinoma specimens (diastase-resistant periodic acid Schiff stain; $\times 400$, A: negative; B: positive). c-f Immunohistochemical staining of stage I adenocarcinoma specimens with antibodies specific for 116-NS-19-9. Representative staining patterns for $\mathbf{c}$ : intensity 0; $\mathbf{d}$ : intensity 1 ; e: intensity 2; and f: intensity $3(\times 400)$

statistical analyses on JMP software ( $11^{\text {th }}$ version; SAS Institute, Cary, NC, USA).

\section{Results}

\section{Patient characteristics}

We included 246 patients with ALAD in the study (Fig. 2). Patient characteristics and comparison of clinical profiles of CA $19-9^{+}$and CA $19-9^{-}$patients are shown in Table 1. Their median age was 67 years (interquartile range, 61-75 years); 184 (75 \%) patients had Eastern Cooperative Oncology Group Performance Status (ECOG PS) of 0 or 1; and $26(11 \%)$ patients had stage IIIB disease. Of the 246 patients, 100 (41\%) had EGFR mutations in their specimens, and $22(9 \%)$ had chronic lung inflammatory diseases
(16 with interstitial pneumonia, 3 with NTM infection, and 3 with bronchiectasis). We found $163(66 \%)$ were $\mathrm{CEA}^{+}$ (>5.0 ng/ml), 155 (63\%) were CYFRA $21-1^{+}(>2.2 \mathrm{ng} / \mathrm{ml})$ and $76(31 \%)$ were CA $19-9^{+}(>37.0 \mathrm{U} / \mathrm{mL})$. Chemotherapy regimens of patients who did not receive platinum doublet therapy were tyrosine kinase inhibitors: $n=34$; pemetrexed: $n=18$; TS-1: $n=6$; paclitaxel: $n=5$; vinorelbine: $n=4$; gemcitabine: $n=4$; docetaxel: $n=3$; and gemcitabine/ vinorelbine therapy: $n=2$.

Comparison of clinical profiles of CA $19-9^{-}$and CA $19-9^{+}$patients showed the CA $19-9^{-}$group included a significantly higher percentage of patients with ECOG PS 0 or 1 status $(P<0.001)$, serum CYFRA $21-1^{-}(P=0.002)$, and platinum doublet therapy administration $(P=0.007)$. EGFR

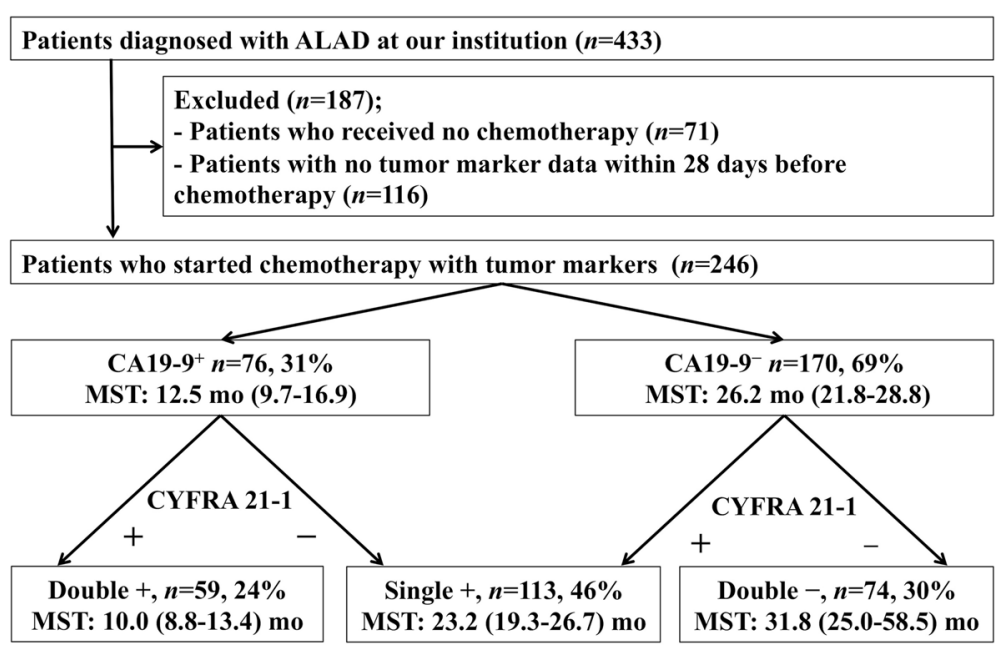

Fig. 2 Patient selection and exclusion criteria. Patients were stratified into 3 groups by their serum tumor markers: double positive (Double + ): CA 19-9 $9^{+}$CYFRA $21-1^{+}$; single positive (Single +): either CA $19-9^{+}$or CYFRA $21-1^{+}$; and double negative (Double -): CA 19-9 $/$CYFRA $21-1^{-}$. Median survival time of each group is indicated in months (with ranges). ALAD: advanced lung adenocarcinoma; CYFRA 21-1: cytokeratin 19 fragments; CA 19-9: carbohydrate antigen 19-9; + positive; -: negative; MST: median survival time 
Table 1 Characteristics and differences by serum CA 19-9 levels in patients with advanced-stage lung adenocarcinoma

\begin{tabular}{|c|c|c|c|c|}
\hline Patient characteristics & Total $n(\%)(n=246)$ & CA 19-9 positive $n(\%)(n=76)$ & CA 19-9 negative $n(\%)(n=170)$ & $P$ \\
\hline \multicolumn{5}{|l|}{ Age (years) } \\
\hline SD & 10.4 & 10.7 & 10.2 & \multirow[t]{2}{*}{0.160} \\
\hline Mean & 67.1 & 68.5 & 66.5 & \\
\hline \multicolumn{5}{|l|}{ Sex } \\
\hline Male & $154(63)$ & $47(62)$ & $107(63)$ & \multirow[t]{2}{*}{0.887} \\
\hline Female & $92(37)$ & $29(38)$ & $63(37)$ & \\
\hline \multicolumn{5}{|l|}{ Smoking status } \\
\hline Never & $101(41)$ & $29(38)$ & $72(42)$ & \multirow[t]{2}{*}{0.577} \\
\hline Current or former & $145(59)$ & $47(62)$ & $98(58)$ & \\
\hline \multicolumn{5}{|l|}{ ECOG PS } \\
\hline 0 or 1 & $184(75)$ & $46(61)$ & $138(81)$ & \multirow[t]{2}{*}{$<0.001$} \\
\hline $2-4$ & $62(25)$ & $30(39)$ & $32(19)$ & \\
\hline \multicolumn{5}{|l|}{ Stage } \\
\hline$\| I B$ & $26(11)$ & $6(8)$ & $20(12)$ & \multirow[t]{2}{*}{0.501} \\
\hline IV & $220(89)$ & $70(92)$ & $150(88)$ & \\
\hline \multicolumn{5}{|l|}{ EGFR status } \\
\hline Mutated & $100(41)$ & $30(39)$ & $70(41)$ & \multirow[t]{5}{*}{$0.888^{*}$} \\
\hline Exon 19 deletion & $45(18)$ & $16(21)$ & $29(17)$ & \\
\hline Exon 21 point mutation & $48(20)$ & $11(14)$ & $37(22)$ & \\
\hline Others & $7(3)$ & $3(4)$ & $4(2)$ & \\
\hline WT or uninvestigated & $146(59)$ & $46(61)$ & $100(59)$ & \\
\hline \multicolumn{5}{|l|}{ Inflammatory lung disease } \\
\hline Present & $22(9)$ & $10(13)$ & $12(7)$ & \multirow[t]{2}{*}{0.147} \\
\hline Absent & $224(91)$ & $66(87)$ & $158(93)$ & \\
\hline \multicolumn{5}{|l|}{ Serum CEA } \\
\hline Positive & $163(66)$ & $53(70)$ & $110(65)$ & \multirow[t]{2}{*}{0.469} \\
\hline Negative & $83(34)$ & $23(30)$ & $60(35)$ & \\
\hline \multicolumn{5}{|l|}{ Serum CYFRA 21-1 } \\
\hline Positive & $155(63)$ & $59(78)$ & $96(56)$ & \multirow[t]{2}{*}{0.002} \\
\hline Negative & $91(37)$ & $17(22)$ & $74(44)$ & \\
\hline \multicolumn{5}{|l|}{ Chemotherapy } \\
\hline Platinum doublet & $170(69)$ & $43(57)$ & $127(75)$ & \multirow[t]{2}{*}{0.007} \\
\hline Others & $76(31)$ & $33(43)$ & $43(25)$ & \\
\hline
\end{tabular}

CA 19-9 carbohydrate antigen 19-9, CEA carcinoembryonic antigen, CYFRA 21-1 cytokeratin 19 fragments, ECOG PS Eastern Cooperative Oncology Group Performance Status, EGFR epidermal growth factor receptor gene, SD standard deviation, WT wild-type

*Comparison between patients with mutated EGFR and those with WT or uninvestigated EGFR

status $(P=0.888)$ and presence of inflammatory lung disease $(P=0.147)$ did not statistically differ between the two groups.

Clinical profiles of CYFRA 21-1 ${ }^{-}$and CYFRA 21-1 ${ }^{+}$ patients are compared in (Additional file 1: Table S1). The CYFRA $21-1^{-}$group had a significantly higher percentage of patients with ECOG PS 0 or 1 status $(P=0.002)$, inflammatory lung disease $(P=0.020)$, serum CA $19-9^{-}$ $(P=0.002)$, and platinum doublet therapy administration $(P=0.046)$. EGFR status $(P=0.502)$ did not statistically differ between the two groups.
Test of correlation between CA 19-9 levels and CYFRA 21-1 levels showed no significant relationship between these tumor markers $(r=0.006)$. The scatter plot is shown in (Additional file 2: Figure S1).

\section{Survival analysis according to the tumor markers}

The OS of patients included in this study was 21.4 months (interquartile range, 18.9-25.0 months; Table 2). Overall survival curves of CA $19-9^{+}$and CA $19-9^{-}$patients are shown in Fig. 3a. The OS of serum CA $19-9^{+}$patients 
Table 2 Analysis of overall survival time by clinical factors

\begin{tabular}{|c|c|c|c|c|c|}
\hline \multirow[t]{2}{*}{ Characteristics } & \multirow{2}{*}{$\begin{array}{l}\text { Patients } \\
n(\%)\end{array}$} & \multirow{2}{*}{$\begin{array}{l}\text { OS } \\
\text { (months) }\end{array}$} & \multirow{2}{*}{$\begin{array}{l}\text { Univariate analysis } \\
P\end{array}$} & \multicolumn{2}{|c|}{ Multivariate analysis } \\
\hline & & & & HR $(95 \%$ Cl) & $P$ \\
\hline \multicolumn{6}{|l|}{ Age (years) } \\
\hline$\geq 75$ & $62(25)$ & 15.1 & 0.005 & $1.35(0.90-1.99)$ & 0.150 \\
\hline$<75$ & $184(75)$ & 24.2 & & Reference & \\
\hline \multicolumn{6}{|l|}{ Sex } \\
\hline Male & $154(63)$ & 19.1 & 0.279 & $1.30(0.87-1.97)$ & 0.204 \\
\hline Female & $92(37)$ & 26.2 & & Reference & \\
\hline \multicolumn{6}{|l|}{ Smoking status } \\
\hline Never & $101(41)$ & 23.8 & 0.742 & $0.91(0.64-1.36)$ & 0.636 \\
\hline Current or former & $145(59)$ & 19.3 & & Reference & \\
\hline \multicolumn{6}{|l|}{ ECOG PS } \\
\hline 0 or 1 & $184(75)$ & 26.5 & $<0.001$ & $0.42(0.29-0.62)$ & $<0.001$ \\
\hline $2-4$ & $62(25)$ & 8.8 & & Reference & \\
\hline \multicolumn{6}{|l|}{ EGFR status } \\
\hline Mutated & $100(41)$ & 31.1 & 0.001 & $0.41(0.29-0.57)$ & $<0.001$ \\
\hline WT or uninvestigated & $146(59)$ & 16.9 & & Reference & \\
\hline \multicolumn{6}{|l|}{ Stage } \\
\hline$\| I \mathrm{~B}$ & $26(11)$ & 43.9 & 0.016 & $0.38(0.21-0.64)$ & $<0.001$ \\
\hline IV & $220(89)$ & 20.2 & & Reference & \\
\hline \multicolumn{6}{|l|}{ Serum CEA } \\
\hline Negative & $83(34)$ & 20.4 & 0.985 & $0.79(0.56-1.11)$ & 0.180 \\
\hline Positive & $163(66)$ & 21.8 & & Reference & \\
\hline \multicolumn{6}{|l|}{ Serum CYFRA 21-1 } \\
\hline Negative & $91(37)$ & 31.8 & $<0.001$ & $0.47(0.32-0.66)$ & $<0.001$ \\
\hline Positive & $155(63)$ & 16.9 & & Reference & \\
\hline \multicolumn{6}{|l|}{ Serum CA 19-9 } \\
\hline Negative & $170(69)$ & 26.2 & $<0.001$ & $0.60(0.43-0.85)$ & 0.005 \\
\hline Positive & $76(31)$ & 12.5 & & Reference & \\
\hline \multicolumn{6}{|l|}{ Chemotherapy } \\
\hline Platinum doublet & $170(69)$ & 25.0 & $<0.001$ & $0.64(0.42-0.97)$ & 0.034 \\
\hline Others & $76(31)$ & 14.2 & & Reference & \\
\hline
\end{tabular}

CA 19-9 carbohydrate antigen 19-9, CEA carcinoembryonic antigen, Cl confidence interval, CYFRA 21-1 cytokeratin 19 fragments, ECOG PS Eastern Cooperative Oncology Group Performance Status, EGFR epidermal growth factor receptor gene, WT wild-type, HR hazard ratio, OS overall survival

$(n=170,69 \%)$ was 12.5 months (95\% CI [CI]: $9.7-$ 16.9 months); that of serum CA $19-9^{-}$patients $(n=76$, $31 \%)$ was 26.2 months (CI: $21.8-28.8$ months; $P<0.001)$. The OS of serum CYFRA $21-1^{+}$patients $(n=155,63 \%)$ was 16.9 months (CI: $12.6-19.7$ months), and that of serum CYFRA $21-1^{-}$patients $(n=91,37 \%)$ was 31.8 months (CI: $26.2-43.9$ months; $P<0.001)$.

\section{Multivariate analysis of overall survival time}

Cox's multivariate regression analysis of the influence of clinical characteristics on survival outcomes indicated that ECOG PS 0 or 1 (HR: 0.42, CI: $0.29-0.62, P<0.001$ ), mutated EGFR status (HR: 0.41, CI: $0.29-0.57, P<0.001$ ), stage IIIB (HR: $0.38, \mathrm{CI}: 0.21-0.64, P<0.001$ ), serum CYFRA $21-1^{-}$(HR: 0.47, CI: $\left.0.32-0.66, P<0.001\right)$, serum CA $19-9^{-}$(HR: $0.60, \mathrm{CI}: 0.43-0.85, P=0.005$ ), and administration of platinum doublet therapy (HR: $0.64, \mathrm{CI}$ : $0.42-0.97, P=0.034)$ independently predicted longer OS. To clarify the relationships of chemotherapy regimens to OS, we analyzed the platinum doublet subcohorts with regard to OS; we found that CA $19-9^{-}$independently predicted longer OS (HR: 0.54, CI:0.35 - 0.84, $P=0.007$ ).

OS by combined serum levels of CA 19-9 and CYFRA 21-1 We initially divided the patients into 4 groups by serum CA 19-9 and CYFRA 21-1 level: (a) both CA 19-9 ${ }^{+}$and 

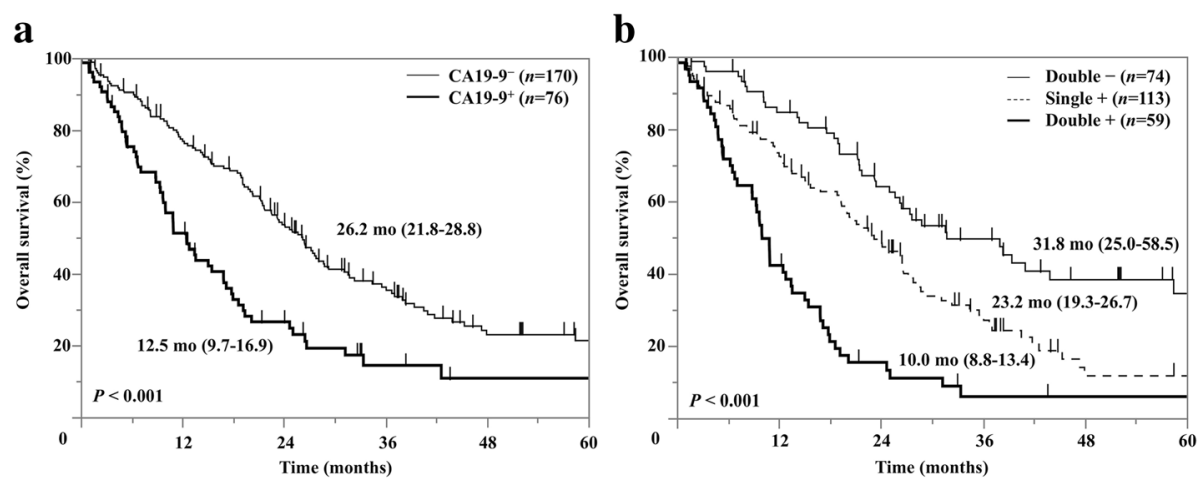

Fig. 3 Kaplan-Meier curves for overall survival in patients with advanced stage disease, by (a) serum CA 19-9 positivity; and (b) both serum CA 19-9 and serum CYFRA 21-1 (Double -: neither marker; Single +: one marker; Double +: both markers)

CYFRA $21-1^{+}$(59 patients, $24 \%$; median survival time [MST]: 10.0 months [CI: 8.8 - 13.4 months]), (b) CA 19-9+ and CYFRA $21-1^{-}$(17 patients, $7 \%$; MST: 26.7 months [CI: $12.5{ }^{-}$* months]), (c) CA 19-9 ${ }^{-}$and CYFRA $21-1^{+}$(96 patients, $39 \%$; MST: 22.5 months [CI: 16.9 - 26.6 months]), and (d) both CA 19-9- and CYFRA 21-1- (74 patients, $30 \%$; MST: 31.8 months [CI: $25.0-58.5$ months]). Although the MSTs of (a) and (b) $(P=0.001)$ and that of (c) and $(\mathrm{d})(P=0.003)$ differed statistically, the difference between the two single-positive groups, (b) and (c), was not significant $(P=0.14)$. Therefore, we combined groups (b) and (c) into one single positive group. We also defined group (a) as double positive and group (d) as double negative (Fig. 2). Survival curves for these 3 groups are shown in Fig. 3b. Their MSTs were double positive: 10.0 months (CI: 8.8 - 13.4 months); single positive: 23.2 months (CI: 19.3 - 26.7 months); and double negative: 31.8 months (CI: $25.0-58.5$ months; $P<0.001$ ).

Pathological findings and recurrence-free survival analysis We pathologically evaluated 116 consecutive surgically resected specimens from patients with clinical stage I lung adenocarcinoma. Of those, 54 (47 \%) were CA $19-9^{+}$. Relationships between CA 19-9 expression and patients' clinicopathological characteristics are summarized in Table 3. Comparison of clinical profiles of CA $19-9^{+}$and CA $19-9^{-}$patients showed the CA $19-9^{+}$ group to include significantly higher proportions of patients with vessel invasion $(P=0.032)$, pleural invasion $(P=0.023)$, cancer invasive factors $(P=0.005)$ and positive PAS stain $(P=0.001)$. CA $19-9^{+}$patients had significantly shorter recurrence-free survival than CA $19-9^{-}$patients $(P=0.030)$. The Kaplan-Meier curve is shown in Fig. 4. We also investigated the association between EGFR status and survival in the 116 patients with stage I lung adenocarcinoma; for whom 110 (95\%) had EGFR mutation analyses available, which showed 61 (53\%) to have EGFR mutations. Log-lank analysis revealed that EGFR status had no prognostic effect on recurrence-free survival $(P=0.569)$, or OS $(P=0.171)$.

\section{Discussion}

In the present study, we showed that both serum CA 19-9 and CYFRA 21-1 were independent prognostic markers in ALAD patients, and their combined use improves prognostic accuracy.

We have shown serum CA 19-9 to be an independent predictive factor for OS, according to multivariate analysis of possible prognostic factors that included serum CYFRA 21-1. To the best of our knowledge, this is the first report to show the correlation between positive CA 19-9 levels and shorter OS in patients with ALAD, although this correlation has been reported in adenocarcinomas of other organs such as pancreas, colon, and stomach [8-15]. The consistency of this pattern among adenocarcinomas of different organs implies that serum CA 19-9 might be a prognostic marker in all kinds of adenocarcinoma.

The major advantage of CA 19-9 is that it can be measured quickly at low cost. Additionally, CA 19-9 is a standard biomarker for gastrointestinal cancers, such as pancreatic, colon, and gastric cancers. Therefore we speculate that its application to lung cancer would be relatively easy.

Our results also showed that $31 \%$ of ALAD patients had positive serum CA 19-9. We believe that this positive rate is common in patients with ALAD, although it was much lower than in studies of patients with advanced pancreatic adenocarcinoma (for which CA 19-9 is a prognostic marker), who were reportedly $50 \%-84 \%$ positive $[8,10,30]$.

The combined use of CA 19-9 and CYFRA 21-1 offers more accurate prognoses in patients with lung adenocarcinoma. In our study, as patients who were either CA $19-9^{+}$or CYFRA $21-1^{+}$did not significantly differ in 
Table 3 Relationships between serum CA 19-9 and clinicopathological factors in clinical stage I lung adenocarcinoma patients

\begin{tabular}{|c|c|c|c|}
\hline Patient characteristics & CA 19-9 positive $n(\%)(n=54)$ & CA 19-9 negative $n(\%)(n=62)$ & $P$ \\
\hline \multicolumn{4}{|l|}{ Age (years) } \\
\hline SD & 9.1 & 8.3 & \multirow[t]{2}{*}{0.028} \\
\hline Mean & 69.2 & 65.6 & \\
\hline \multicolumn{4}{|l|}{ Sex } \\
\hline Male & $29(54)$ & $30(48)$ & \multirow[t]{2}{*}{0.582} \\
\hline Female & $25(46)$ & $32(52)$ & \\
\hline \multicolumn{4}{|l|}{ Smoking status } \\
\hline Never & $30(56)$ & $32(52)$ & \multirow[t]{2}{*}{0.712} \\
\hline Current or former & $24(44)$ & $30(48)$ & \\
\hline \multicolumn{4}{|l|}{ Vessel invasion } \\
\hline Absent & $39(72)$ & $55(89)$ & \multirow[t]{2}{*}{0.032} \\
\hline Present & $15(28)$ & $7(11)$ & \\
\hline \multicolumn{4}{|l|}{ Pleural invasion } \\
\hline Absent & $41(76)$ & $57(92)$ & \multirow[t]{2}{*}{0.023} \\
\hline Present & $13(24)$ & $5(8)$ & \\
\hline \multicolumn{4}{|l|}{$\mathrm{p}-\mathrm{N}$ status } \\
\hline No metastasis & $47(87)$ & $59(95)$ & \multirow[t]{2}{*}{0.184} \\
\hline Metastasis & $7(13)$ & $3(5)$ & \\
\hline \multicolumn{4}{|l|}{ Cancer invasive factor } \\
\hline Negative & $29(54)$ & $49(79)$ & \multirow[t]{2}{*}{0.005} \\
\hline Positive & $25(46)$ & $13(21)$ & \\
\hline \multicolumn{4}{|l|}{ c-Stage ${ }^{a}$} \\
\hline IA & $44(81)$ & $50(81)$ & \multirow[t]{2}{*}{1.000} \\
\hline IB & $10(19)$ & $12(19)$ & \\
\hline \multicolumn{4}{|l|}{$p$-Stage ${ }^{b}$} \\
\hline I & $45(83)$ & $59(95)$ & \multirow[t]{2}{*}{0.063} \\
\hline$\|/\| \|$ & $9(17)$ & $3(5)$ & \\
\hline \multicolumn{4}{|l|}{ PAS stain } \\
\hline Negative & $32(59)$ & $54(87)$ & \multirow[t]{2}{*}{0.001} \\
\hline Positive & $22(41)$ & $8(13)$ & \\
\hline
\end{tabular}

CA 19-9 carbohydrate antigen 19-9, PAS periodic acid-Schiff stain, SD standard deviation

${ }^{\mathrm{a}}$ Clinical stage; ${ }^{\mathrm{b}}$ Pathological stage

survival, we regarded them as one group (single positive patients). Consequently, we divided patients into three groups as well; $24 \%$ double positive (CA 19-9+/CYFRA $21-1^{+}$), $46 \%$ single positive (either CA $19-9^{+}$or CYFRA $21-1^{+}$), and $30 \%$ double negative (CA 19-9-/CYFRA $21-1^{-}$). Survival curves for these 3 groups revealed significant relationships between these tumor markers and prognosis (Fig. 3b).

The precise reason for high CA 19-9 levels is unclear. However, large studies have shown that healthy volunteers did not have high serum CA 19-9 levels [31, 32]. High CA 19-9 elevation has been reported in some chronic inflammatory lung diseases, such as intestinal pneumonia, NTM infection, bronchiectasis, and diffuse panbronchiolitis [33]. In the present study, CA 19-9 positivity and presence of inflammatory disease showed no correlation $(P=0.147)$; thus inflammatory disease did not cause CA 19-9 elevation. In addition, our pathological analysis demonstrated that the lung cancer cells generated CA 19-9. Therefore, we speculated the elevated serum CA 19-9 was associated with the CA 19-9 generated by cancer cells.

Although CA 19-9 expression is also related to unfavorable prognosis in some kinds of cancer, why high CA 19-9 predict shorter OS is not understood [34, 35]. We therefore investigated the relationship between CA 19-9 IHC positivity and pathological findings in patients with stage I lung adenocarcinoma. We analyzed the presence of 


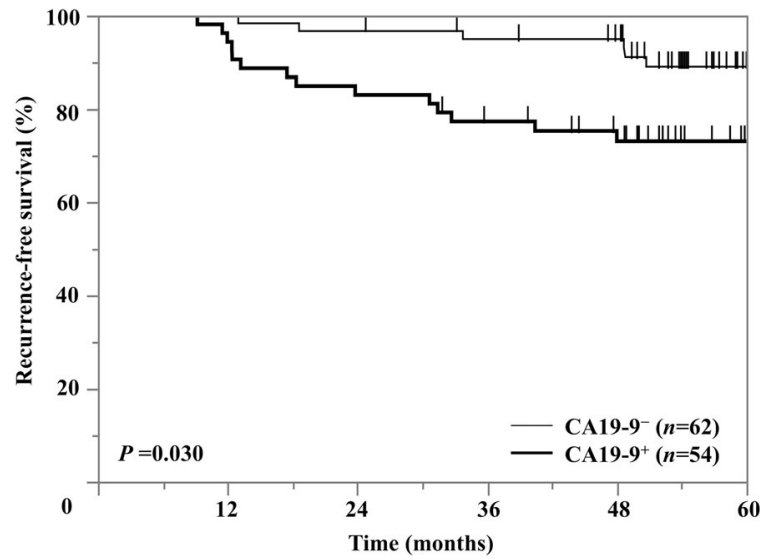

Fig. 4 Kaplan-Meier curves for recurrence-free survival by histological CA 19-9 positivity in patients with stage I lung adenocarcinoma

cancer invasive factors (vessel and pleural invasion) and mucin production, which were reportedly associated with highly malignant features such as shorter recurrence-free survival and $O S$ in lung adenocarcinoma patients $[24,29,36]$. In our pathological analysis of clinical stage I patients, CA 19-9 positive lung adenocarcinoma had more histologically malignant features $(P=0.005)$ and shorter recurrence-free survival $(P=0.030)$ than CA 19-9 negative lung adenocarcinoma (Fig. 4). These findings indicate that CA 19-9 positive lung adenocarcinoma is highly malignant. We speculate that these malignant features caused the elevated serum CA 19-9, as cancer cell invasion to the blood could cause the elevated serum tumor markers.

Our findings are of special interest, but there were some limitations to this study. First, as this study was conducted in a single institute, it included limited number of patients. Second, a considerable number of patients were excluded from this analysis due to missing tumor marker data before their initial therapy, because measurement of tumor markers was at the discretion of the attending physician. Third, subject selection in this study was confined to Japanese patients, and racial differences may need to be considered in the interpretation of this study. Fourth, we did not examine Lewis antigen status [37]. Patients who are Lewis antigen-negative cannot synthesize CA 19-9, and therefore present as falsely negative [38]. However, as they comprise only $5-7 \%$ of the general population, we assume that it did not affect the results [39].

\section{Conclusions}

In conclusion, our study showed serum CA 19-9 to be an independent prognostic indicator in patients with ALAD, and combined use of CA 19-9 and CYFRA 21-1 to provide more accurate prognostic information.

\section{Additional files}

Additional file 1: Table S1. Characteristics and differences by serum CYFRA 21-1 levels in patients with advanced-stage lung adenocarcinoma. (DOCX $24 \mathrm{~kb}$ )

Additional file 2: Figure S1. Scatter-plot of serum CA 19-9 and CYFRA 21-1 levels. (JPG 394 kb)

\section{Abbreviations}

ALAD: Advanced lung adenocarcinoma; CA 19-9: Carbohydrate antigen 19-9; CEA: Carcinoembryonic antigen; Cl: Confidence interval; CLEIA: Chemiluminescent enzyme immunoassay; CYFRA 21-1: Cytokeratin 19 fragments; ECOG PS: Eastern Cooperative Oncology Group Performance Status; EGFR: Epidermal growth factor receptor gene; HR: Hazard ratio; IHC: Immunohistochemical; MST: Median survival time; NSE: Neuron-specific enolase; NTM: Non-tuberculous mycobacteriosis; OS: Overall survival; PAS: Periodic acid Schiff; SD: Standard deviation; TNM: Tumor, node, metastasis; ULN: Upper limit of normal

\section{Acknowledgements}

The authors would like to thank Keiko Sakuragawa (Department of Respiratory Medicine, Kobe City Medical Center General Hospital, Kobe, Japan) for her administrative assistance and Syuji Imoto (Department of Pathology, Kobe City Medical Center General Hospital, Kobe, Japan) for pathological analysis.

Funding

The authors received no financial support for present work.

\section{Availability of data and materials}

The data that support the findings of this study are available from the corresponding author upon reasonable request.

\section{Authors' contributions}

YS contributed to the drafting of this manuscript and data collection. DF is the guarantor of the paper, taking responsibility for the integrity of the work as a whole, from inception to the published article. KU and Yl carried out the pathological analysis. RS contributed to the study design and statistical analysis. JI, MK, ST, RK, KN, AN, KO, HH, YT, and KT contributed to analysis of the data and interpretation of the findings. All authors have read and approved of the submission of the final manuscript.

\section{Competing interests}

The authors declare that they have no competing interests.

\section{Consent for publication}

Not applicable.

\section{Ethics approval and consent to participate}

This study was conducted with the approval of the Kobe City Medical Center General Hospital Ethics Committee (No. 15053). All tumor specimens enrolled in the pathological analysis were obtained with informed consent (or formal waiver of consent) with approval by our Ethics Committee. The informed consent was waived from individual participants enrolled in the retrospective study part.

\section{Author details}

'Department of Respiratory Medicine, Kobe City Medical Center, General Hospital, 2-1-1 Minatojima-minamimachi, Chuo-ku, Kobe 650-0047, Japan. ${ }^{2}$ Department of Pathology, Kobe City Medical Center, General Hospital, 2-1-1 Minatojima-minamimachi, Chuo-ku, Kobe 650-0047, Japan. ${ }^{3}$ Department of Thoracic Surgery, Kobe City Medical Center, General Hospital, 2-1-1 Minatojima-minamimachi, Chuo-ku, Kobe 650-0047, Japan.

Received: 9 November 2015 Accepted: 30 October 2016 Published online: 14 November 2016

\section{References}

1. Siegel RL, Miller KD, Jemal A. Cancer statistics, 2015. CA Cancer J Clin. 2015;65(1):5-29.

2. Malvezzi M, Bertuccio P, Rosso T, Rota M, Levi F, La Vecchia C, Negri E. European cancer mortality predictions for the year 2015: does lung cancer have the highest death rate in EU women? Ann Oncol. 2015;26(4):779-86. 
3. Sturgeon C. Practice guidelines for tumor marker use in the clinic. Clin Chem. 2002;48(8):1151-9.

4. Ono A, Takahashi T, Mori K, Akamatsu H, Shukuya T, Taira T, Kenmotsu H, Naito T, Murakami H, Nakajima T, et al. Prognostic impact of serum CYFRA 21-1 in patients with advanced lung adenocarcinoma: a retrospective study. BMC Cancer. 2013;13:354.

5. Barlesi F, Gimenez C, Torre JP, Doddoli C, Mancini J, Greillier L, Roux F, Kleisbauer JP. Prognostic value of combination of Cyfra 21-1, CEA and NSE in patients with advanced non-small cell lung cancer. Respir Med. 2004:98(4):357-62.

6. Nisman B, Lafair J, Heching N, Lyass O, Baras M, Peretz T, Barak V. Evaluation of tissue polypeptide specific antigen, CYFRA 21-1, and carcinoembryonic antigen in nonsmall cell lung carcinoma: does the combined use of cytokeratin markers give any additional information? Cancer. 1998;82(10):1850-9.

7. Koprowski H, Steplewski Z, Mitchell K, Herlyn M, Herlyn D, Fuhrer P. Colorectal carcinoma antigens detected by hybridoma antibodies. Somatic Cell Genet. 1979;5(6):957-71.

8. Hess V, Glimelius B, Grawe P, Dietrich D, Bodoky G, Ruhstaller T, Bajetta E, Saletti P, Figer A, Scheithauer W, et al. CA 19-9 tumour-marker response to chemotherapy in patients with advanced pancreatic cancer enrolled in a randomised controlled trial. Lancet Oncol. 2008;9(2):132-8.

9. Maisey NR, Norman AR, Hill A, Massey A, Oates J, Cunningham D. CA19-9 as a prognostic factor in inoperable pancreatic cancer: the implication for clinical trials. Br J Cancer. 2005;93(7):740-3.

10. Zhao JG, Hu Y, Liao Q, Niu ZY, Zhao YP. Prognostic significance of SUVmax and serum carbohydrate antigen 19-9 in pancreatic cancer. World J Gastroenterol. 2014;20(19):5875-80.

11. Hammad N, Heilbrun LK, Philip PA, Shields AF, Zalupski MM, Venkatramanamoorthy R, El-Rayes BF. CA19-9 as a predictor of tumor response and survival in patients with advanced pancreatic cancer treated with gemcitabine based chemotherapy. Asia Pac J Clin Oncol. 2010;6(2):98-105.

12. Reiter W, Stieber P, Reuter C, Nagel D, Lau-Werner U, Lamerz R. Multivariate analysis of the prognostic value of CEA and CA 19-9 serum levels in colorectal cancer. Anticancer Res. 2000;20(6D):5195-8.

13. Nozoe T, Rikimaru T, Mori E, Okuyama T, Takahashi I. Increase in both CEA and CA19-9 in sera is an independent prognostic indicator in colorectal carcinoma. J Surg Oncol. 2006;94(2):132-7.

14. Sato H, Usuda N, Kuroda M, Hashimoto S, Maruta M, Maeda K. Significance of serum concentrations of E-selectin and CA19-9 in the prognosis of colorectal cancer. Jpn J Clin Oncol. 2010;40(11):1073-80.

15. Kochi M, Fujii M, Kanamori N, Kaiga T, Kawakami T, Aizaki K, Kasahara M, Mochizuki F, Kasakura Y, Yamagata M. Evaluation of serum CEA and CA19-9 levels as prognostic factors in patients with gastric cancer. Gastric Cancer. 2000;3(4):177-86.

16. Faruqi S, Gumparthy K, Wahbi Z. Elevated CA 19-9 levels observed in association with a pulmonary neuroendocrine tumour and amyloid. Intern Med. 2013;52(1):105-9.

17. Nakajima T, Terashima T, Nishida J, Onoda M, Koide O. Treatment of bronchorrhea by corticosteroids in a case of bronchioloalveolar carcinoma producing CA19-9. Intern Med. 2002;41(3):225-8.

18. Goldstraw P, Crowley J, Chansky K, Giroux DJ, Groome PA, Rami-Porta R, Postmus PE, Rusch V, Sobin L, International Association for the Study of Lung Cancer International Staging C, et al. The IASLC Lung Cancer Staging Project: proposals for the revision of the TNM stage groupings in the forthcoming (seventh) edition of the TNM Classification of malignant tumours. J Thorac Oncol. 2007;2(8):706-14.

19. Nagai $Y$, Miyazawa H, Huqun, Tanaka T, Udagawa K, Kato M, Fukuyama S, Yokote A, Kobayashi K, Kanazawa M, et al. Genetic heterogeneity of the epidermal growth factor receptor in non-small cell lung cancer cell lines revealed by a rapid and sensitive detection system, the peptide nucleic acid-locked nucleic acid PCR clamp. Cancer Res. 2005;65(16):7276-82.

20. Nishizono I, lida S, Suzuki N, Kawada H, Murakami H, Ashihara Y, Okada M. Rapid and sensitive chemiluminescent enzyme immunoassay for measuring tumor markers. Clin Chem. 1991;37(9):1639-44.

21. Kuroda M, Aizu M, Shimazu C, Miyazawa Y. Evaluation of CYFRA 21-1 measurement by fully automated chemiluminescent immunoassay system "Lumipulse Presto". J Clin Lab Inst Reag. 2006;29(6):597-602.

22. Kuroda M, Aizu M, Shimazu C, Miyazawa Y. Evaluation of tumor markers measurement by fully automated chemiluminescent immunoassay system "Lumipulse Presto". Jpn J Med Pharm Sci. 2006;56(5):757-64.
23. Kuroda M, Aizu M, Shimazu C, Miyazawa Y. Evaluation of CA 19-9 measurement by fully automated chemiluminescent immunoassay system "Lumipulse Presto". Jpn J Med Pharm Sci. 2006;56(5):765-70.

24. Duruisseaux M, Antoine M, Rabbe N, Poulot V, Fleury-Feith J, Vieira T, Lavole A, Cadranel J, Wislez M. The impact of intracytoplasmic mucin in lung adenocarcinoma with pneumonic radiological presentation. Lung Cancer. 2014;83(3):334-40.

25. Nicholson AG, Gonzalez D, Shah P, Pynegar MJ, Deshmukh M, Rice A, Popat S. Refining the diagnosis and EGFR status of non-small cell lung carcinoma in biopsy and cytologic material, using a panel of mucin staining, TTF-1, cytokeratin 5/6, and P63, and EGFR mutation analysis. J Thorac Oncol. 2010;5(4):436-41.

26. Allred DC, Clark GM, Elledge R, Fuqua SA, Brown RW, Chamness GC, Osborne CK, McGuire WL. Association of p53 protein expression with tumor cell proliferation rate and clinical outcome in node-negative breast cancer. J Natl Cancer Inst. 1993;85(3):200-6.

27. Azuma K, Okamoto I, Kawahara A, Taira T, Nakashima K, Hattori S, Kinoshita T, Takeda M, Nakagawa K, Takamori S, et al. Association of the expression of mutant epidermal growth factor receptor protein as determined with mutation-specific antibodies in non-small cell lung cancer with progressionfree survival after gefitinib treatment. J Thorac Oncol. 2012;7(1):122-7.

28. Lantuejoul S, Rouquette I, Blons H, Le Stang N, Ilie M, Bequeret H, Gregoire V, Hofman P, Gros A, Garcia S, et al. French multicentric validation of ALK rearrangement diagnostic in 547 lung adenocarcinomas. Eur Respir J. 2015; 46(1):207-18.

29. Shimada Y, Yoshida J, Hishida T, Nishimura M, Ishii G, Nagai K. Predictive factors of pathologically proven noninvasive tumor characteristics in T1aN0M0 peripheral non-small cell lung cancer. Chest. 2012;141(4):1003-9.

30. Pelzer U, Hilbig A, Sinn M, Stieler J, Bahra M, Dorken B, Riess H. Value of carbohydrate antigen 19-9 in predicting response and therapy control in patients with metastatic pancreatic cancer undergoing first-line therapy. Front Oncol. 2013;3:155.

31. Kim JE, Lee KT, Lee JK, Paik SW, Rhee JC, Choi KW. Clinical usefulness of carbohydrate antigen 19-9 as a screening test for pancreatic cancer in an asymptomatic population. J Gastroenterol Hepatol. 2004;19(2):182-6.

32. Tong $Y$, Song Z, Zhu W. Study of an elevated carbohydrate antigen 19-9 concentration in a large health check-up cohort in China. Clin Chem Lab Med. 2013;51(7):1459-66

33. Kodama T, Satoh H, Ishikawa H, Ohtsuka M. Serum levels of CA19-9 in patients with nonmalignant respiratory diseases. J Clin Lab Anal. 2007;21(2):103-6.

34. Dorandeu A, Raoul JL, Siriser F, Leclercq-Rioux N, Gosselin M, Martin ED, Ramee MP, Launois B. Carcinoma of the ampulla of Vater: prognostic factors after curative surgery: a series of 45 cases. Gut. 1997;40(3):350-5.

35. Hsu CC, Goyal A, luga A, Krishnamoorthy S, Lee V, Verna EC, Wang S, Chen FN, Rodriguez R, Emond J, et al. Elevated CA19-9 is associated with increased mortality in a prospective cohort of hepatocellular carcinoma patients. Clin Transl Gastroenterol. 2015;6:e74.

36. Lakshmanan I, Ponnusamy MP, Macha MA, Haridas D, Majhi PD, Kaur S, Jain M, Batra SK, Ganti AK. Mucins in lung cancer: diagnostic, prognostic, and therapeutic implications. J Thorac Oncol. 2015;10(1):19-27.

37. Le Pendu J, Marionneau S, Cailleau-Thomas A, Rocher J, Le Moullac-Vaidye $\mathrm{B}$, Clement M. ABH and Lewis histo-blood group antigens in cancer. APMIS 2001;109(1):9-31.

38. Vestergaard EM, Hein HO, Meyer H, Grunnet $\mathrm{N}$, Jorgensen J, Wolf H, Orntoft TF. Reference values and biological variation for tumor marker CA 19-9 in serum for different Lewis and secretor genotypes and evaluation of secretor and Lewis genotyping in a Caucasian population. Clin Chem. 1999;45(1):54-61.

39. Tempero MA, Uchida E, Takasaki H, Burnett DA, Steplewski Z, Pour PM. Relationship of carbohydrate antigen 19-9 and Lewis antigens in pancreatic cancer. Cancer Res. 1987;47(20):5501-3. 